\title{
Retrograde Jejunogastric Intussusception: A Case Report
}

\author{
SS Pervin ${ }^{1}$, SK Biswas $^{2}$, S Ahmed $^{3}$, D Khandokar ${ }^{4}$
}

\begin{abstract}
Jejunogastric Intussusceptions is a rare but potentially life threatening complication of a previous gastrectomy or gastrojejunostomy. A 70 years old man presented with severe epigastric pain followed by haematemesis, 8 years after truncal vagotomy and gastrojejunostomy for pyloric stenosis. Ultrasonography revealed dilated stomach with a large intragastric mass which has minimal peristaltic movement. Endoscopy of upper GIT revealed prolapsed segment of jejunal loops through the gastrojejunostomy stoma. Laparotomy disclosed a retrograde type II jejunogastric intussusception and was managed by reduction of jejunogastric intussusception, resection of gangrenous segment and end to end anastomosis. Post operative recovery was uneventful. Retrograde jejunogastric intussusceptions is a rare condition and around 200 cases has been reported since its first description in 1914. Urgent recognition and surgical treatment is mandatory to reduce the mortality rate from this complication.
\end{abstract}

Key words: Retrograde Jejunogastric Intussusception, gastrojejunostomy, gastric surgery.

\section{Introduction}

Retrograde Jejunogastric Intussusception is an uncommon but potentially life threatening complication of gastrojejunostomy or partial gastrectomy which may occur any time after primary surgery ${ }^{1,2}$. Usual clinical presentations of patient are severe epigastric pain, vomiting and haematemesis with history of previous gastric surgery. Bozzi described the first case of this complication in 1914. Around 200 cases have been reported in English literature till now ${ }^{3,4}$. We present a case report of retrograde jejunogastric intussusception with characteristic ultrasonographic and endoscopic finding.

\section{Case Report}

A 70 yrs old man presented with acute abdominal pain and vomiting and haematemesis. He has undergone gastrojejunostomy operation for pyloric stenosis 8 years back. He was asymptomatic until his recent admission

1. Dr. Salma Shanawaz Pervin, MD (Radiology \& Imaging), Assistant Professor, Dept. of Radiology \& Imaging, FMC, Faridpur.

2. Dr. Swapan Kumar Biswas, FCPS (Surgery), MRCS (Edin), Junior Consultant, Dept. of Surgery, FMC, Faridpur.

3. Dr. Saad Ahmed, M Phil (Radiology \& Imaging), Junior Consultant, Radiology \& Imaging, General Hospital, Kushtia.

4. Dr. Dilruba Khandokar, MD (Radiology \& Imaging), Assistant Professor, Dept. of Radiology \& Imaging, EMC, Savar, Dhaka.

Address of correspondence

Dr. Salma Shanawaz Pervin, MD (Radiology \& Imaging)

Assistant Professor, Dept. of Radiology \& Imaging, FMC, Faridpur.

Phone: $+88-01711862750$ to the emergency ward. Patient was dehydrated; with pulse rate $110 / \mathrm{min}$ and $\mathrm{BP} 100 / 60 \mathrm{~mm}$ of $\mathrm{Hg}$. Patient has an upper midline scar. Epigastric region was distended and there was a vague feeling of epigastric mass. Laboratory investigation showed haemoglobin $13.4 \mathrm{gm} \%$, RBS $6.7 \mathrm{mmol} / \mathrm{L}, \mathrm{S}$. Creatinine $1.6 \mathrm{mg} / \mathrm{dl}$, White cell count $16,800 / \mathrm{cmm}$ with $87 \%$ polymorph, ESR $32 \mathrm{~mm}$ is $1^{\text {st }}$ hour, Plain X-ray abdomen was within normal limit. Ultrasonography of abdomen showed hugely distended stomach filled with fluid and a large intragastric mass with minimal peristaltic within the mass (Figure 1). After initial resuscitation, upper GIT endoscopy was performed which revealed the classic scenario of retrograde jejunogastric Intussusception (Figure 2).

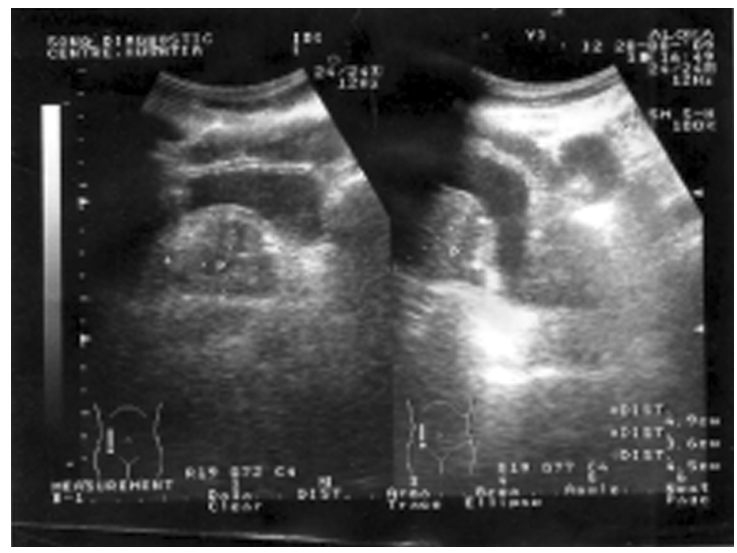

Figure 1: USG shows the presence of jejunal loops with in dilated fluid filled stomach. 
There was a posterior stoma of gastrojejunostomy and prolapsed jejunal loops through it.
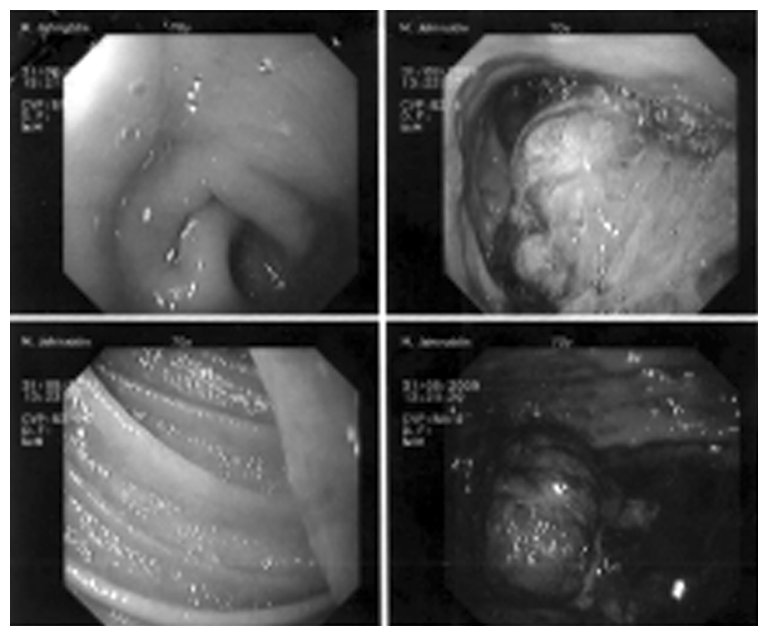

Figure 2: Gastric endoscopy shows a lobulated congestive mass which consistent with jejunogastric intussusception.

After initial resuscitative measures with intravenous fluid, blood transfusion, nasogastric suction and antibiotics, emergency laparotomy was carried out. At operation, stomach was found hugely distended with an intraluminal mass. The presence of posterior gastrojejunostomy was confirmed with intussusception of efferent jejunal loop into the stomach. A gastrostomy was done which revealed intussuscepted gangrenous efferent jejunal loop. Then intussusception was reduced, the gangrenous segment was resected with end to end jejunal anastomosis was made. Finally gastrostomy wound was repaired and in two layers. The patient had an uneventful postoperative recovery and was discharged on day 8.

\section{Discussion}

Retrograde jejunogastric intussusception is a rare but serious complication after gastric surgery where small bowel loops get incarcerated and strangulated inside the stomach $^{1,2}$. It was first described by Bozzi in a patient with gastroenterostomy ${ }^{5}$. Eight years later this complication was also reported in a patient with Billroth II resection ${ }^{6}$. Subsequently, a large number of isolated cases and small series have been published ${ }^{1-4,7}$. Thus, jejunogastric intussusception seems to be a rare complication after gastrojejunostomy or Billroth II gastrectomy; it also has been described in association with previously placed gastrostomy tube ${ }^{8}$, after total gastrectomy $^{9}$, after Billroth I operation ${ }^{1}$ and after Roux-en-Y gastric bypass ${ }^{10}$. The widely accepted anatomical classification proposed by Shackman ${ }^{11}$ distinguishes three categories of jejunogastric intussusception; Type - I: afferent loop intussusception (antegrade), Type - II: efferent loop intussusception (retrograde) and Type - III: combined form. Type II or retrograde efferent loop intussusception is the most common (80\%) with two other types accounting for $10 \%{ }^{1,12}$. In the case presented, a type II jejunogastric intussusception was documented.

The mechanism of jejunogastric intussusception is poorly understood ${ }^{1-3}$. Two major theories are functional and mechanical. The most widely accepted functional theory is the disordered motility with functional hyperperistalsis triggered by spasm or hyperacidity ${ }^{7,13}$. Mechanical factors include adhesions leading to intussusception of a more mobile segment into fixed segments, a long mesentery, gastric derangements and sudden increase in abdominal pressure ${ }^{3,7,13}$.

Two forms of jejunogastric intussusception have been clinically recognized: an acute and chronic form ${ }^{1,3,7}$. In the acute form, incarceration and strangulation of the intussuscepted loop generally occur whilst spontaneous reduction is usual in chronic type. The classical triad of acute jejunogastric intussusceptions includes sudden onset of epigastric pain, vomiting with or without haematemesis and a palpable epigastric mass in a patient who has undergone previous gastric surgery ${ }^{1,3,7,14}$. The picture was absolutely typical in the case described here. The chronic form may present with symptoms similar to the acute form, but the symptoms may be milder and transient and may subside spontaneously ${ }^{1,3,7}$. There is wide variation in the lapse time between the gastric operation and the jejunogastric intussusception to occur; the shortest reported interval is two days and the longest is 55 years $^{7,15}$. Eight years was lapse time in the present case.

In acute form of jejunogastric intussusception, a plain $\mathrm{x}$-ray of the abdomen may show a homogenous density in the left upper quadrant that represents small bowel in the stomach ${ }^{13}$. Ultrasonography is the method of first choice of investigation because it can be performed at beside without ionizing radiation and is cost effective. It shows intragastric tubular image with or without peristalsis ${ }^{7}$. CT scan also shows a dilated stomach with intragastric filling by bowel loop ${ }^{12}$. Contrast X-rays of stomach using water soluble dyes also confirms the diagnosis showing filling defect with in stomach and in type II jejunogastric intussusception, well delineation of duodenal $\mathrm{C}$ loop with non visualization of efferent jejunal loop ${ }^{12,13}$. Endoscopy, performed by someone familiar with this care entity, will certainly be diagnostic $^{13}$. Most reported cases of jejunogastric 
intussusception were diagnosed at surgery ${ }^{4,14-16}$, so it requires high index of suspicion. In our case typical features and ultrasonographic and endoscopic findings enable us to make preoperative diagnosis. In chronic form, for correct diagnosis to be made, upper GI imaging should be performed during the symptomatic period $^{12}$.

Treatment of the acute variety of jejunogastric intussusception is prompt surgery after resuscitation. At operation, if the intussuscepted jejunum is viable, then simple reduction is performed. To prevent recurrence, the reduced jejunum is fixed to either the afferent limb of the gastrojejunal anastomosis or the transverse mesocolon $^{3,7,13,14}$. If the bowel is nonviable it must be resected, as in this patient. The treatment of chronic recurrent variety of jejunogastric intussusception is symptomatic. If the symptom persists then revisional surgery may have to be performed ${ }^{13,14}$.

\section{Conclusion}

Jejunogastric intussusception is a very serious lifethreatening complication of gastric surgery. There is a wide variation in the lapse time between the gastric surgery and occurrence of jejunogastric intussusception. When a patient who has had history of gastric operation present with epigastric pain, vomiting and haematemesis, the possibility of a jejunogastric intussusception should be considered along with more common diagnosis such as recurrent stomach ulcer. Because this condition is life threatening awareness of this rare complication is essential to save life by operative intervention.

\section{References}

1. Archimandritis AJ, Hatzopoulos N, Hatzinikolaou P, Sougioultzis S, Kourtesas D, Papastratis G, et al. jejunogastric intussusception presented with haematemesis: a case presentation and review of literature. BMC Gastroenterology 2001;1:1-4.

2. Bapaye M, Kolte S, Pai K, Godse A, Pardeshi A, Bhave A, et al. Jejunogastric intussusception presenting with outlet obstruction. Indian J Gastroenterol. 2008;22:31-2.

3. Kshirsagar AY, Shinde SL, Langade YB, Pujari SG, Jeur AS. Retrograde jejunogastric intussusception with strangulation after posterior gastrojejunostomy. MJAFI 2008;64:282-283.

4. Hasan M, Mahamud MM, Khan SA, Rahman M. Jejunogastric intussusception. Mymensingh Med J. 2009;18(2):255-9.

5. Bozzi E. Annotation, Bull Acad Med. 1914;122:3-4.

6. Lundburg S. Retrograde Dunndarminvagination nach Gastroenterostomie. Acta chir Sand. 1922;54:423-433.

7. Tkue H, Tsushima Y, Arai Y, Endo K. Jejunogastric intussusception: Life threatening complication occurring 55 years after gastrojejunostomy. Inter Med. 2009;48:1657-1660.
8. Gasparri MG, Pipinos II, Kralovich KA, Margilin DA. Retrograde jejunogastric intussusception. South M J. 2000;93:499-500.

9. Freeman J, Bernatz P, Brown P. Retrograde intussusception after total gastrectomy. Arch Surg. 1966;93:586-588.

10. Goverman J Greenwald M, Gellman L, Gadaleta D. Antiperistatic (retrograde) intussusception after Roux-en-Y gastric bypass. J Am Coll Surg. 2004;199:988-989.

11. Shackman R. Jejunogastric intussusception. Brit J Surg. 1940;27:475-480.

12. Vohra P, Arora A, Parikh N, Vaghani M, Vaghela P, Vaidya V, et al. Retrograde jejunogastric intussusception. Ind J Radiol Imag. 2005;15(4):493-495.

13. Samarasam I, Chandran B, Shanker U, George B, Chacko A, Mathew G. Jejunogastric intussusception: An unusual cause of haematemesis. Can J Gastroenterol. 2005;19(12):735-736.

14. Miah AG, Imam NA, Joarder RH, Talukder SI, Hossain MS. Retrograde jejunogastric intussusception (JGI) with strangulation following previous gastrojejunostomy. Mymensingh Med J. 2006;15(1):99-101.

15. Gupta SS, Singh GG. Retrograde jejunogastric intussusception: an unusual cause of haematemesis (a case report). J Postgrade Med. 1986;32:105-6.

16. Conklin EF, Markowits AM. Intussusception, a complication of gastric surgery. Surgery 1965;7:480-8. 